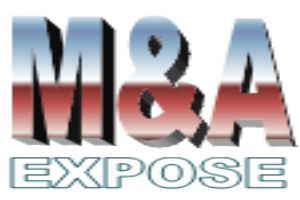

http://jurnal.usahid.ac.id/index .php/accounting
${ }^{1}$ Fakultas Ekonomi dan Bisnis Universitas Sahid susybhudiharty@gmail.com

\section{Analisis Kualitas Pelayanan dan Kepuasan Pengunjung Objek Wisata Farmhouse Lembang}

\author{
Susy Bhudiharty ${ }^{1}$
}

\section{Abstrak}

Tujuan penelitian ini adalah untuk menganalisis kualitas pelayanan dan kepuasan pengunjung di Farmhouse Lembang. Kualitas pelayanan dianalisis berdasarkan dimensi berwujud (tangible), keandalan (realibility), daya tanggap (responsiveness), jaminan (assurance), dan empati (empathy). Adapun kepuasan pengunjung dianalisis berdasarkan dimensi kesesuaian harapan, minat berkunjung kembali, dan bersedia merekomendasikan. Teknik analisis deskriptif dilakukan atas kuesioner yang diisi 100 orang pengunjung. Hasil penelitian menunjukkan kualitas pelayanan dilihat dari dimensi berwujud (tangible) adalah baik, dimensi keandalan (reliablity) adalah "sangat baik", dimensi daya tanggap (responsiveness) adalah "sangat baik", dimensi jaminan (assurance) adalah "baik", dan empati (empathy) adalah "sangat baik". Adapun penilaian pengunjung terhadap kepuasan berdasarkan ketiga dimensi berada dalam kategori "sangat puas".

Kata kunci : kualitas pelayanan, kepuasan pengunjung.

\section{Abstract}

The purpose of this study was to analyze the quality of service and visitor satisfaction at Lembang Farmhouse. Service quality is analyzed based on the dimensions of tangible, reliability, responsiveness, assurance, and empathy. The visitor satisfaction is analyzed based on the dimensions of the suitability of expectations, interest in visiting again, and willing to recommend. Descriptive analysis technique was carried out on a questionnaire filled with 100 visitors. The results showed that service quality seen from tangible dimensions was good, reliability dimensions were "very good", responsiveness was "very good", assurance was "good", and empathy is "very good". The visitor's assessment of satisfaction based on all three dimensions is in the "very satisfied" category.

Keywords: service quality, customer satisfaction. 


\section{PENDAHULUAN}

Farmhouse Lembang memiliki daya tarik wisata berupa Taman Bunga dan Rumah Hobbit Kurcaci. Selain itu wisatawan juga bisa berinteraksi dengan kuda, kelinci, aneka burung, sugar glider, iguana dan masih banyak binatang lainya. Terdapat juga jembatan yang sisi kanan dan kirinya bisa dipasangi gembok cinta, yang merupakan daya tarik khusus bagi para remaja.

Farmhouse Lembang didirikan oleh PT. Perisai Utama Grup pada tahun 2015, merupakan manajemen yang sama dengan Rumah Sosis, D' ranch, Tahu Susu Lembang, Floating Market Lembang dan Hijab Swimming Pool. Farmhouse Lembang menyediakan tempat wisata bercita rasa Eropa dan Rumah Hobbit ala Hobbiton di New Zealand. Objek wisata Farmhouse Lembang menyediakan segala keunikan dan fasilitas yang dapat memberikan kepuasan tersendiri bagi para pengunjungnya.

Banyaknya objek wisata di sekitar Lembang menimbulkan persaingan usaha, yang membuat Framhouse Lembang harus mampu bersaing agar bisa bertahan dengan segala keunikannya. Hubungan yang baik akan tercipta apabila usaha bisnis mampu memberikan kepuasan kepada pengunjungnya melalui pelayanan yang dihasilkan sehingga pengunjung akan setia kembali lagi, yang pada akhirnya membuat perusahaan terus tumbuh dan berkembang. Kepuasan pengunjung dianggap sangat penting karena hasil penjualannya bersumber dari dua kelompok dasar, yaitu pengunjung baru dan pengunjung yang datang kembali. Maka objek wisata akan berusaha agar dapat mempertahankan pengunjung yang ada agar selalu merasa senang dan puas. Indikasi kepuasan pengunjung dapat dilihat dari pengunjung memberikan rekomendasi kepada temannya atau tamu yang berkunjung kembali.

Pada data berikut, dapat dilihat bahwa jumlah pengunjung ke objek wisata Farmhouse Lembang mengalami fluktuasi.

Tabel 1. Jumlah pengunjung Farmhouse Lembang periode November 2017 - Oktober 2018

\begin{tabular}{lcrc}
\hline Bulan & Tahun & Pengunjung(orang) & Persentase(\%) \\
\hline November & 2017 & 582.107 orang & - \\
Desember & 2017 & 547.253 orang & $-0,64 \%$ \\
Januari & 2018 & 521.104 orang & $-0,50 \%$ \\
Februari & 2018 & 302.407 orang & $-0,73 \%$ \\
Maret & 2018 & 211.317 orang & $-0,44 \%$ \\
April & 2018 & 200.102 orang & $-0,57 \%$ \\
Mei & 2018 & 312.406 orang & $0,36 \%$ \\
Juni & 2018 & 605.817 orang & $0,49 \%$ \\
Juli & 2018 & 610.111 orang & $0,71 \%$ \\
Agustus & 2018 & 427.000 orang & $-0,43 \%$ \\
September & 2018 & 300.246 orang & $-0,43 \%$ \\
Oktober & 2018 & 251.834 orang & $-0,20 \%$ \\
\hline
\end{tabular}

Sumber: Farmhouse, 2018 
Dari tabel 1 dapat dilihat bahwa selama 1 (satu) tahun dari bulan November 2017 sampai dengan bulan Oktober 2018 terjadi kenaikan dan penurunan jumlah pengunjung pada objek wisata Farmhouse Lembang. Terjadi penurunan jumlah pengunjung sebanyak 2,88\% pada bulan November 2017 hingga April 2018, kemudian mengalami kenaikan jumlah pengunjung pada bulan Mei 2018 hingga Juli 2018 sebesar 1,56\% yang sebagian besar kenaikan dipengaruhi oleh musim liburan anak sekolah dan kemudian mengalami penurunan kembali pada bulan Agustus 2018 hingga Oktober 2018 sebanyak 1,06\%.

Tabel 2. Keluhan pengunjung Farmhouse Lembang, November 2017 - Oktober 2018

\begin{tabular}{|c|c|c|}
\hline No & Indikator & Keluhan Pengunjung \\
\hline 1 & Fasilitas & $\begin{array}{l}\text { - Toilet tidak sesuai dengan kapasitas bila } \\
\text { - Jeekend dan musim libur. } \\
\text { tempat (Mini Zoo, Kebun bunga). } \\
\text { - Harga makanan \& minuman restaurant di dalam } \\
\text { farmhouse Lembang cukup mahal. } \\
\text { - Tempat-tempat yang banyak diminati } \\
\text { pengunjung untuk berfoto selfie/wefie sulit } \\
\text { dijangkau bila weekend \& musim libur karena } \\
\text { sangat padat oleh pengunjung. } \\
\text { - Tempat parkir sangat terbatas. }\end{array}$ \\
\hline 2 & Akses & $\begin{array}{l}\text { Farmhouse Lembang dari kota Bandung berjarak } \\
\text { kurang lebih } 15,2 \mathrm{~km} \text { itu lumayan jauh bila libur } \\
\text { panjang \& weekend terjadi kepadatan \& kemacetan } \\
\text { yang cukup panjang menuju farmhouse Lembang }\end{array}$ \\
\hline
\end{tabular}

Dapat dilihat dari fasilitas, pengunjung mengeluhkan toilet, jalur pejalan kaki, tempattempat untuk berfoto, tempat parkir kurang memadai dan juga untuk harga makanan dan minuman yang masih cukup mahal sedangkan dari akses, pengunjung mengeluhkan terjadi kemacetan dan kepadatan bila weekend dan musim libur. Farmhouse Lembang harus mencari solusi untuk permasalahan di atas dan memiliki inovasi dan kreatifitas agar dapat memberikan kepuasan tersendiri bagi pengunjung. Salah satu faktor penunjang untuk memuaskan para pengunjung adalah melalui pelayanan dengan memberikan pelayanan yang baik maka dapat meningkatkan jumlah peminat agar datang berkunjung kembali dan menikmati fasilitas yang disuguhkan.

\section{TINJAUAN PUSTAKA}

Kualitas Pelayanan. Baik tidaknya kualitas pelayanan jasa sangat tergantung pada kemampuan penyedia jasa dalam memenuhi harapan konsumen secara konsisten. Menurut American Society for Quality Control yang mengatakan "Quality is the totality of features and characteristics of a product or service that bear on its ability to satisty stated of implied 
needs" yang berarti kualitas adalah keseluruhan dari fitur dan karakteristik dari sebuah produk atau jasa yang memiliki kemampuan untuk memuaskan kebutuhan.

Menurut Zeithaml, Berry dan Parasuraman dalam Tjiptono (2014:198) terdapat 5 (lima) dimensi kualitas pelayanan jasa, yaitu :

1. Bukti fisik (tangible)

Bukti fisik merupakan dimensi yang berkenan dengan daya tarik fasilitas fisik, perlengkapan, dan material yang digunakan perusahaan, serta penampilan karyawan. Penampilan dan kemampuan sarana serta prasarana fisik perusahaan dan keadaan lingkungan sekitarnya adalah bukti nyata dari pelayanan yang diberikan oleh pemberi jasa. Wujud fisik yang baik akan mempengaruhi persepsi konsumen. Semakin bagus fasilitas fisik yang disediakan bagi konsumen maka semakin besar pula harapan konsumen pada perusahaan pemberi jasa tersebut. Contohnya dalam jasa objek wisata, fasilitas bersih dan indah serta seluruh karyawannya mengenakan seragam yang bersih, wangi dan rapi.

2. Kehandalan (reability)

Kehandalan adalah kemampuan perusahaan untuk memberikan pelayanan sesuai dengan apa yang dijanjikan secara akurat dan terpercaya. Kinerja harus sesuai dengan harapan konsumen yang berarti ketepatan waktu, pelayanan yang sama untuk semua pengunjung tanpa kesalahan, sikap yang simpatik, dan dengan akurasi yang tinggi. Pemenuhan janji dalam pelayanan akan mencerminkan kredibilitas perusahaan dimensi kehandalan sering di persepsikan menjadi yang paling penting bagi pengunjung dari beragam industri jasa, karena apabila konsumen merasakan bahwa keandalan suatu perusahaan jasa sangat sesuai dengan harapan, maka mereka akan bersedia mengeluarkan biaya tambahan agar perusahaan melaksanakan transaksi seperti yang dijanjikan. Bila dikaitkan dengan bidang usaha jasa objek wisata, maka karyawan yang bekerja selalu memberikan pelayanan sesuai dengan standard operasional perusahaan.

3. Daya Tanggap (responsiveness)

Dimensi daya tanggap adalah dimensi yang paling dinamis. Harapan konsumen hampir dapat dipastikan akan berubah seiring dengan kecepatan daya tanggap dari pemberi jasa. Daya tanggap berkenaan dengan kesedian dan kemampuan para karyawan untuk membantu para konsumen dan merespons permintaan mereka, serta menginformasikan kapan jasa akan diberikan dan kemudian memberikan jasa secara cepat. Tingkat kesediaan atau kepedulian ini akan dilihat sampai sejauh mana pihak perusahaan berusaha dalam membantu konsumenya. Adapun bentuknya bisa dilakukan dengan penyampaian informasi yang jelas, tindakan yang dapat dirasakan manfaatnya oleh pengunjung. Sebagai contoh dalam usaha jasa objek wisata, pengunjung tidak harus menunggu pelayanan yang lama dan kecepatan dalam mengangani keluhan yang disampaikan oleh pengunjung.

4. Jaminan/Kepastian (Assurance)

Jaminan atau kepastian yaitu jaminan kepada konsumen mencakup kemampuan, kesopanan dan sifat dapat dipercaya yang dimilki oleh para staf, bebas dari bahaya atau resiko keragu-raguan, perilaku para karyawan diharapkan mampu menumbuhkan kepercayaan dan perusahaan diharapkan dapat menumbuhkan rasa aman bagi pelanggannya. Contohnya seperti jaminan kesehatan, asuransi dari bank. 


\section{Analisis Kualitas Layanan dan Kepuasan Pengunjung ....}

Susy Bhudiharty

\section{Empati (empathy)}

Empati adalah memberikan sikap yang tulus dan bersifat individual atau pribadi yang diberikan kepada para pengunjung dengan berupaya memahami keinginan pengunjung. Di mana suatu perusahaaan diharapkan memiliki pengertian dan pengetahuan tentang pengunjung, memahami kebutuhan pengunjung secara spesifik, serta memiliki waktu pengeoperasian yang nyaman bagi pengunjung. Inti dari dimensi empati adalah menunjukan kepada pengunjung melalui layanan yang diberikan bahwa pengunjung itu spesial dan kebutuhan mereka dapat dipahami

Kepuasan Pengunjung. Kepuasan pengunjung merupakan suatu tanggapan perilaku pengunjung berupa evaluasi terhadap suatu fasilitas atau jasa yang dirasakan dibanding dengan harapan pengunjung. Menurut Zulian (2013:5) Bahwa kepuasan pengunjung adalah hasil (outcome) yang dirasakan atas penggunaan produk dan jasa, sama atau melebihi harapan yang diinginkan.

Kepuasan pengunjung berkaitan erat dengan mutu. Mutu mempunyai dampak langsung pada prestasi fasilitas dan dengan demikian juga dengan kepuasan pengunjung. Kepuasan pengunjung tergantung pada anggapan kinerja fasilitas dalam menyerahkan nilai relatif terhadap harapan pengunjung. Bila fasilitas jauh lebih rendah ketimbang dengan harapan pengunjung, maka konsumen akan merasa tidak puas. Bila prestasi sesuai dengan harapan, pengunjung fasilitas akan merasa puas. Bila prestasi melebihi harapan, pengunjung akan merasa amat puas. Pengunjung yang merasa puas akan membeli ulang dan pengunjung tersebut akan memberi tahu orang lain mengenai pengalaman baik dengan fasilitas tersebut. Kuncinya adalah memenuhi harapan pengunjung dengan prestasi perusahaan. Perusahaan yang cerdik mempunyai tujuan membuat pengunjung merasa sangat puas dengan menjanjikan pelayanan yang baik dan memberikan lebih baik dari yang dijanjikan. Secara konseptual, kepuasan, dan ketidakpuasan dapat dikaji dari teori :

1. Pengalaman efektif atau perasaan (experience affective fellings)

Pengalaman efektif atau perasaan yaitu teori yang berpandangan bahwa ketidakpuasan dipengaruhi oleh perasaan positif dan negatif yang diasosiasikan pengunjung terhadap fasilitas dan jasa tertentu setelah pembelian. Dengan kata lain, pemahaman kognitif mengenai diskonfirmasi harapan yang timbul dalam proses purna beli mempengaruhi kepuasan itu sendiri.

2. Expectancy Disconfirmation Theory

Teori diskonfirmasi harapan yaitu teori menunjukan evaluasi pengalaman yang dirasakan (kinerja) sama baiknya (sesuai) dengan yang di harapkan. Pengunjung membentuk harapan mengenai kinerja suatu fasilitas tertentu. Harapan atas kinerja dibandingkan dengan kinerja aktual fasilitas (yakni persepsi terhadap kualitas fasilitas).

3. Attribution Theory

Teori atribusi mengidentifikasikan proses yang dilakukan dalam menentukan penyebab tindakan, orang lain dan objek tertentu. Atribusi yang dilakukan mempengaruhi kepuasan purna beli terhadap fasilitas tertentu, karena atribusi memoderasi perasaan puas atau tidak puas.

Terdapat 3 (tiga) atribusi pelanggan :

a. Casual attribution, Yaitu apabila terjadi kesalahan, pelanggan segera menilai pihak yang patut disalahkan.

b. Control attribution, Yaitu pelanggan menilai ketidakpuasan berada dalam kendali pemasar 
c. Stability attribution, Yaitu pengunjung menilai kejadian berulang apabila kepuasan terjadi.

Menurut Tjiptono (2014 : 101), dimensi pembentuk kepuasan pengunjung terdiri dari tiga komponen berikut :

1. Kesesuaian Harapan

Kesesuaian harapan merupakan tingkat kesesuaian antara kinerja fasilitas yang diharapkan pengunjung dengan yang dirasakan pengunjung, meliputi :

a. Fasilitas yang diperoleh sesuai dengan harapan pengunjung.

b. Pelayanan yang di lakukan oleh karyawan sesuai dengan yang diharapkan.

2. Minat Berkunjung Kembali

Minat berkunjung kembali merupakan tingkat kepuasan pengunjung yang mendorongnya untuk berkunjung kembali lain waktu, meliputi :

a. Berminat berkunjung kembali karena merasa puas dengan pelayanan yang diberikan oleh penyedia jasa.

b. Berminat untuk berkunjung kembali karena fasilitas yang disediakan memadai.

3. Kesediaan Merekomendasikan

Merupakan kesediaan pengunjung untuk merekomendasikan fasilitas yang telah dirasakannya kepada kerabat atau keluarga, meliputi :

a. Merekomendasikan kerabat dan keluarga untuk membeli fasilitas yang dihasilkan tempat tersebut karena pelayanannya yang memuaskan.

b. Merekomendasikan kerabat dan keluarga untuk membeli fasilitas yang dihasilkan tempat tersebut karena sesuai dengan harapan

Menurut Kotler dalam Tjiptono dan Chandra (2012:314), metode yang dapat digunakan untuk mengukur kepuasan pengunjung yaitu :

1. Sistem Keluhan dan Saran

Media yang digunakan dapat berupa kotak saran yang diletakkan di tempat yang strategis (yang mudah untuk diakses atau sering di lalui pengunjung), Form komentar, saluran telepon khusus bebas pulsa, website, dll.

2. Ghost Shopping / Mystery Shopping

Seseorang yang diberi tugas atau manajer sendiri yang turun berperan sebagai pelanggan potensial dan melaporkan berbagai temuan penting baik terhadap karyawan sendiri ataupun terhadap pengunjung.

3. Analisis Konsumen yang Hilang (Lost Customer Analiys)

Perusahaan harus menguhubungi para pengunjung yang sudah tidak pernah datang atau beralih kepada perusahaan lain.

4. Survey Kepuasan Pelanggan

Dengan cara melakukan survey dan wawancara langsung, maka akan terlihat dan mendengar sendiri bagaimana tanggapan dan umpan balik lagsung dari pengunjung dan juga memberikan sinyal positif bahwa perusahaan menaruh perhatian terhadap mereka. Pengukuran kepuasan pengunjung melalui metode ini dapat dilakukan dengan berbagai cara, diantaranya :

a. Directly reported satisfaction

Pengukuran yang dilakukan dengan mengunakan item-item spesifik yang menanyakan lansung tingkat kepuasan yang dirasakan pelanggan. 


\section{b. Derived satisfaction}

Pengukuran yang dilakukan dengan mengajukan dua hal utama, yakni besarnya harapan pengunjung terhadap atribut tertentu dan besarnya kinerja yang mereka rasakan.

c. Importance - performance analisys

Dalam teknik ini responden diminta untuk merangking berbagai elemen dari penawaran berdasarkan derajat pentingnya setiap elemen tersebut. Selain itu responden juga diminta merangking seberapa baik kinerja perusahaan dalam masing-masing elemen atau atribut.

\section{METODE PENELITIAN}

Penelitian ini menggunakan analisa deskriptif dengan sampel sebanyak 100 orang. Adapun operasional variabelnya adalah sebagai berikut :

Tabel 1. Operasional Variabel

\begin{tabular}{|c|c|c|c|}
\hline Variabel & Dimensi & Indikator & $\begin{array}{c}\text { Skala } \\
\text { Pengukuran }\end{array}$ \\
\hline \multirow{2}{*}{$\begin{array}{c}\text { Kualitas } \\
\text { Pelayanan } \\
\text { Menurut } \\
\text { Zeithaml, Barry, } \\
\text { dan Pasuraman } \\
\text { dalam Tjiptono } \\
(2012: 198)\end{array}$} & $\begin{array}{l}\text { Keandalan } \\
\text { (Reability) }\end{array}$ & $\begin{array}{ll}\text { - } & \text { Fasilitas fisik gedung yang } \\
\text { baik dan memiliki daya tarik } \\
\text { - } \quad \text { Kesediaan parkir yang } \\
\text { memadai } \\
\text { - } \quad \text { Toilet yang bersih dan baik } \\
\text { - } & \text { Karyawan Farmhouse } \\
& \text { Lembang memiliki sikap } \\
\text { yang simpatik } \\
\text { - } \quad \text { pelayanan yang sama } \\
\text { untuk semua pengunjung } \\
\text { - Informasi yang } \\
\text { disampaikan mudah } \\
\text { dimengerti }\end{array}$ & Skala Likert 1-5 \\
\hline & $\begin{array}{l}\text { Daya Tanggap } \\
\text { (Responsiveness) }\end{array}$ & $\begin{array}{l}\text { - } \quad \text { kesedian dan kemampuan } \\
\text { karyawan untuk membantu } \\
\text { para pengunjung dan } \\
\text { merespons permintaan } \\
\text { mereka. } \\
\text { - kecepatan dalam } \\
\text { menangani keluhan yang } \\
\text { disampaikan oleh } \\
\text { pengunjung. } \\
\text { - Pengunjung mendapatkan } \\
\text { tiket masuk secara mudah } \\
\text { dan cepat }\end{array}$ & Skala Likert 1-5 \\
\hline
\end{tabular}




\begin{tabular}{|c|c|c|c|}
\hline Variabel & Dimensi & Indikator & $\begin{array}{c}\text { Skala } \\
\text { Pengukuran }\end{array}$ \\
\hline \multirow{2}{*}{$\begin{array}{c}\text { Kualitas } \\
\text { Pelayanan } \\
\text { Menurut } \\
\text { Zeithaml, Barry, } \\
\text { dan Pasuraman } \\
\text { dalam Tjiptono } \\
(2012: 198)\end{array}$} & $\begin{array}{c}\text { Jaminan/ } \\
\text { Kepastian } \\
\text { (Assurance) }\end{array}$ & $\begin{array}{l}\text { - Jaminan keamanan } \\
\text { pengunjung selama dalam } \\
\text { kawasan obyek wisata } \\
\text { - } \text { kesopanan dan sifat dapat } \\
\text { dipercaya yang dimilki oleh } \\
\text { para karyawan } \\
\text { - Jaminan ketenangan } \\
\text { pengunjung selama dalam } \\
\text { kawasan obyek wisata }\end{array}$ & \multirow[t]{2}{*}{ Skala Likert 1-5 } \\
\hline & Empati (Empathy) & $\begin{array}{l}\text { - } \text { sikap yang tulus oleh } \\
\text { karyawan dalam menangani } \\
\text { pengunjung } \\
\text { - } \text { berupaya memahami } \\
\text { keinginan konsumen } \\
\text { - Waktu pengoperasian } \\
\text { obyek wisata nyaman bagi } \\
\text { pengunjung }\end{array}$ & \\
\hline \multirow{3}{*}{$\begin{array}{l}\text { Kepuasan } \\
\text { Pengunjung } \\
\text { Menurut } \\
\text { Tjiptono } \\
(2012: 101)\end{array}$} & $\begin{array}{c}\text { Kesesuaian } \\
\text { Harapan }\end{array}$ & $\begin{array}{l}\text { Fasilitas yang diperoleh } \\
\text { sesuai dengan harapan } \\
\text { - Pelayanan yang dilakukan } \\
\text { oleh karyawan sesuai } \\
\text { dengan yang diharapkan } \\
\end{array}$ & \multirow{3}{*}{ Skala Likert 1-5 } \\
\hline & $\begin{array}{l}\text { Minat berkunjung } \\
\text { kembali }\end{array}$ & $\begin{array}{l}\text { Puas dengan pelayanan } \\
\text { yang diberikan karyawan } \\
\text { farmhouse Lembang } \\
\text { - Fasilitas yang disediakan } \\
\text { memadai }\end{array}$ & \\
\hline & $\begin{array}{c}\text { Kesediaan } \\
\text { Merekomendasi- } \\
\text { kan }\end{array}$ & $\begin{array}{l}\text { - } \text { mau merekomendasikan } \\
\text { karena pelayanan yang } \\
\text { memuaskan } \\
\text { - Mau merekomendasikan } \\
\text { kerabat dan keluarga } \\
\text { karena fasilitas yang sesuai } \\
\text { dengan harapan }\end{array}$ & \\
\hline
\end{tabular}

HASIL DAN PEMBAHASAN

Analisis Kualitas Layanan. Hasil penelitian dan pembahasan mengenai variable kualitas layanan adalah sebagaimana tabel berikut: 
Analisis Kualitas Layanan dan Kepuasan Pengunjung .... Susy Bhudiharty

Tabel 2. Analisis Dimensi Kualitas Pelayanan

\begin{tabular}{|c|c|c|c|}
\hline No & Pernyataan & Rata - Rata & Kategori \\
\hline \multicolumn{4}{|c|}{ Berwujud (Tangible) } \\
\hline 1 & $\begin{array}{l}\text { Fasilitas fisik gedung yang baik dan } \\
\text { memiliki daya tarik }\end{array}$ & 4,44 & Sangat Baik \\
\hline 2 & Kesediaan parkir yang memadai & 3,39 & Cukup Baik \\
\hline 3 & Toilet yang bersih dan baik & 4,10 & Baik \\
\hline \multicolumn{4}{|c|}{ Keandalan (Reliablity) } \\
\hline 4 & $\begin{array}{l}\text { Karyawan Farmhouse Lembang } \\
\text { memiliki sikap yang simpatik }\end{array}$ & 4.42 & Sangat Baik \\
\hline 5 & $\begin{array}{c}\text { Pelayanan yang sama untuk semua } \\
\text { pengunjung }\end{array}$ & 4,14 & Baik \\
\hline 6 & $\begin{array}{l}\text { Informasi yang disampaikan mudah } \\
\text { dimengerti }\end{array}$ & 4,34 & Sangat Baik \\
\hline \multicolumn{4}{|c|}{ Daya Tanggap (Responsiveness) } \\
\hline 7 & $\begin{array}{l}\text { Kesedian dan kemampuan para } \\
\text { karyawan untuk membantu para } \\
\text { pengunjung dan merespons } \\
\text { permintaan mereka. }\end{array}$ & 4,20 & Sangat Baik \\
\hline 8 & $\begin{array}{l}\text { Kecepatan dalam menangani } \\
\text { keluhan yang disampaikan oleh } \\
\text { pengunjung }\end{array}$ & 4,26 & Sangat Baik \\
\hline 9 & $\begin{array}{l}\text { Pengunjung mendapatkan tiket } \\
\text { masuk secara mudah dan cepat }\end{array}$ & 4,44 & Sangat Baik \\
\hline \multicolumn{4}{|c|}{ Jaminan/Kepastian (Assurance) } \\
\hline 10 & $\begin{array}{c}\text { Jaminan keamanan pengunjung } \\
\text { selama dalam kawasan obyek wisata }\end{array}$ & 4,26 & Sangat Baik \\
\hline 11 & $\begin{array}{l}\text { Kesopanan dan sifat dapat dipercaya } \\
\text { yang dimilki oleh para karyawan }\end{array}$ & 4,06 & Baik \\
\hline 12 & $\begin{array}{l}\text { Jaminan ketenangan pengunjung } \\
\text { selama dalam kawasan obyek wisata }\end{array}$ & 4,04 & Baik \\
\hline \multicolumn{4}{|c|}{ Empati (Empathy) } \\
\hline 13 & $\begin{array}{l}\text { Sikap yang tulus oleh karyawan } \\
\text { dalam menangani pengunjung }\end{array}$ & 4,18 & Baik \\
\hline 14 & $\begin{array}{c}\text { Karyawan berupaya memahami } \\
\text { keinginan konsumen }\end{array}$ & 4,12 & Baik \\
\hline 15 & $\begin{array}{c}\text { Waktu pengoperasian obyek wisata } \\
\text { nyaman bagi pengunjung }\end{array}$ & 4,44 & Sangat Baik \\
\hline & Rata-rata & 4.18 & Baik \\
\hline
\end{tabular}

Berdasarkan tabel 2 rekapitulasi mengenai dimensi kualitas pelayanan, maka dapat dilihat nilai rata-rata paling rendah adalah indikator berwujud (tangible). Hal itu dilihat bahwa kesediaan parkir yang memadai yang disediakan oleh Farmhouse Lembang belum sangat 
baik, terlebih bila waktu libur anak sekolah dan hari sabtu dan minggu. Rata-rata paling tertinggi adalah indikator empati (empathy). Hal itu dilihat bahwa fasilitas fisik gedung yang baik dan memiliki daya tarik sudah sangat baik dan juga waktu pengoperasian obyek wisata nyaman bagi pengunjung Farmhouse Lembang hal ini perlu dipertahankan. Rata-rata dari dimensi ini berada dalam kategori baik sesuai dengan tabel interval.

Analisis Kepuasan Pengunjung. Kepuasan pengunjung merupakan respon emosional atau kognitif, respon tersebut menyangkut fokus tertentu seperti ekspektasi, produk, pengalaman berkunjung dan seterusnya. Penilaian mengenai kepuasan pengunjung terbagi atas tiga dimensi kepuasan konsumen yang di kemukakan oleh Tjiptono yaitu kesesuaian harapan, minat berkunjung kembali dan bersedia merekomendasikan.

Tabel 3. Analisis Dimensi Kepuasan Pengunjung

\begin{tabular}{|c|c|c|c|}
\hline No & Pernyataan & Rata - Rata & Kategori \\
\hline \multicolumn{4}{|c|}{ Kesesuaian Harapan } \\
\hline 1 & $\begin{array}{c}\text { Fasilitas yang diperoleh sesuai } \\
\text { dengan harapan }\end{array}$ & 4,24 & Sangat Puas \\
\hline 2 & $\begin{array}{c}\text { Pelayanan yang dilakukan oleh } \\
\text { karyawan sesuai dengan yang } \\
\text { diharapkan }\end{array}$ & 4,26 & Sangat Puas \\
\hline \multicolumn{4}{|c|}{ Minat Berkunjung Kembali } \\
\hline 3 & $\begin{array}{c}\text { Puas dengan pelayanan yang } \\
\text { diberikan karyawan Farmhouse } \\
\text { Lembang }\end{array}$ & 4,34 & Sangat Puas \\
\hline 4 & $\begin{array}{l}\text { Fasilitas yang disediakan } \\
\text { memadai }\end{array}$ & 4,10 & Puas \\
\hline \multicolumn{4}{|c|}{ Bersedia Merekomendasikan } \\
\hline 5 & $\begin{array}{l}\text { Mau merkomendasikan karena } \\
\text { pelayanan yang memuaskan }\end{array}$ & 4,32 & Sangat Puas \\
\hline 6 & $\begin{array}{c}\text { Mau merekomendasikan kerabat } \\
\text { dan keluarga karena fasilitas } \\
\text { yang sesuai dengan harapan }\end{array}$ & 4,42 & Sangat Puas \\
\hline & Rata-rata & 4.28 & Sangat puas \\
\hline
\end{tabular}

Berdasarkan tanggapan responden terhadap kepuasan pengunjung, dilihat dari ratarata yang paling terendah adalah indikator minat berkunjung kembali, yaitu fasilitas yang disediakan beberapa ada yang belum memadai sebagai contoh kesediaan tempat parkir dan rata-rata yang paling tertinggi adalah indikator bersedia merekomendasikan, yaitu mau merekomendasikan kerabat dan keluarga karena fasilitas yang sesuai dengan harapan. Rata-rata dari dimensi ini berada dalam kategori sangat puas sesuai dengan tabel interval. Namun, nilai Rata-rata 4,28 agar dapat dipertahankan. 


\section{KESIMPULAN}

Berdasarkan hasil pengolahan data yang telah dilakukan maka dapat ditarik kesimpulan bahwa tanggapan responden terhadap kualitas pelayanan dilihat dari lima dimensi yaitu berwujud (tangible), dari hasil nilai rata-rata dimensi berwujud (tangible) yaitu "baik" yang artinya Farmhouse Lembang perlu meningkatkan kualitas pelayanan dari dimensi tersebut. Keandalan (reliablity), dari hasil nilai rata-rata dimensi keandalan (reliability) yaitu "Sangat Baik" yang artinya Farmhouse Lembang perlu mempertahankan kualitas pelayanan dari dimensi tersebut. Daya tanggap (responsiveness), dari hasil nilai rata-rata dimensi daya tanggap (responsiveness) yaitu "Sangat Baik" yang artinya Farmhouse Lembang perlu mempertahankan kualitas pelayanan dari dimensi tersebut. Jaminan (assurance), dari hasil nilai rata-rata dimensi Jaminan (assurance), yaitu "baik" yang artinya Farmhouse Lembang perlu meningkatkan kualitas pelayanan dari dimensi tersebut. Empati (empathy) dari hasil nilai rata-rata dimensi empati (empathy) yaitu "Sangat Baik" yang artinya Farmhouse Lembang perlu mempertahankan kualitas pelayanan dari dimensi tersebut. Hasil Rata-rata dari dimensi kualitas pelayanan berada pada kategori "Baik" yang artinya kualitas pelayanan dari Farmhouse Lembang baik dalam 5 Dimensi kualitas pelayanan, akan tetapi Farmhouse perlu meningkatkan kualitas pelayanan agar mencapai kategori "Sangat baik" itu akan membuat menjadi lebih baik lagi. Penilaian responden terhadap kepuasan pengunjung dilihat dari tiga dimensi yaitu kesesuaian harapan, minat berkunjung kembali, dan bersedia merekomendasikan. Dari keseluruhan dimensi ini menghasilkan nilai yang berada dalam kategori "sangat puas" yang artinya Farmhouse Lembang perlu mempertahankan kualitas pelayanan dari dimensi tersebut.

\section{DAFTAR PUSTAKA}

Firda, Herisa Septiana. 2017. Analisa Pengaruh Promosi Terhadap Tingkat Penjualan Susu di PT. Industri Susu Alam Murni. Bandung.

Hafsah, Rahma Nur. 2017. Analisis Kualitas Pelayanan dan Kepuasan Konsumen Pada Restoran Johnny Rockets Lotte Shopping Avenue. Jakarta.

Payne, Adrian. 2013. The Essence of Service Marketing (Pemasaran Jasa). Jakarta : Salemba Empat.

Prasetyo, Dwi. 2014. Pengaruh Kualitas Pelayanan Terhadap Kepuasan Pengunjung pada Obyek Wisata Taman Rekreasi Pantai Krtini Rembang. Jakarta.

Tjiptono, Fandi 2014. Pemasaran Jasa. Yogyakarta : CV ANDI OFFSET.

Tjiptono, Fandi dan Chandra, Gregorius. 2012. Service, Quality \& Satisfaction. Yogyakarta : CV ANDI OFFSET.

Widyasari, Novita. 2010. Analisa Kepuasan Pengunjung Dunia Fantasi Ancol Terhadap

Kualitas Pelayanan Wahana Perang Bintang. Jakarta.

Yanti, Sri. 2014. Objek Wisata 34 Provinsi Di Indonesia. Jakarta. 